\title{
Psychological Injury and Law: Editorial Note
}

\author{
Gerald Young
}

Received: 18 January 2009 / Accepted: 23 January 2009 /Published online: 12 February 2009

(C) Springer Science + Business Media, LLC 2009

Keywords Editorial note

In Young (2008), I indicated that the journal would publish a rebuttal to the Butcher et al. (2008) article. In the present issue, Ben Porath et al. (2009) offer their rebuttal, and it is clear that the two sets of authors have quite different opinions on the validity of the Fake Bad Scale (FBS). PIL's journal policy in such cases is to allow both sides to present their best arguments and to let the readers decide. I served as action editor for the rebuttal, but it was accepted for publication by four psychologists, as was the original article of Butcher et al. Reviewers were aware that in the end, it is the journal readers who have to arrive at their own conclusions about the quality of the two papers and the arguments that they present for and against the FBS. In both cases, the set of authors had concerns about the tone of the language used in the other's article. I tried to arrange for alternate wordings in one or two cases in each article. Ultimately, the articles stand as the readers see them. I especially tried to avoid in the articles use of wording that might be construed as ad hominem or otherwise inappropriate, and I will let the readers decide whether some

Many thanks to Andrew Kane and Izabela Schultz for helpful comments on the text.

G. Young $(\triangle)$

Department of Psychology, Glendon College, York University, 2275 Bayview Ave.,

Toronto, Ontario, Canada M4N 3M6

e-mail: gyoung@glendon.yorku.ca wording should have been changed further in either of the articles as they are presented.

In general, in scholarly publications, authors should focus on the scholarly arguments and the empirical evidence or science that underlies them. In the present exchange, this holds true for both articles, but the sets of authors involved hold opposite opinions and express them with intensity. I ask that readers analyze the two articles in question from this perspective and, in particular, address the quality of the scholarly and scientific arguments that are made as well as the validity of the empirical data that are presented. The journal looks forward to the sets of authors' counter-rebuttal and the response to it. We are letting them continue to debate the relative merits of their stances in the journal, with the full intensity that they wish to express, but also expect all authors of articles published in the journal to remain within the bounds of civility that the readers would want.

\section{References}

Ben-Porath, Y. S., Greve, K. W., Bianchini, K. J., \& Kaufmann, P. M. (2009). The MMPI-2 symptom validity scale (FBS) is an empirically-validated measure of over-reporting in personal injury litigants and claimants: reply to Butcher et al. (2008). Psychological Injury and Law, 2(1) (in press). doi:10.1007/s12207-009-9037-4.

Butcher, J. N., Gass, C. S., Cumella, E., Kally, Z., \& Williams, C. L. (2008). Potential for bias in MMPI-2 assessments using the Fake Bad Scale (FBS). Psychological Injury and Law, 1, 191-209.

Young, G. (2008). Psychological injury and law: Editorial introducing a journal and an association. Psychological Injury and Law, 1, $1-6$. 